\title{
Solving a Set of Spherical Equations for Localization of Partial Discharges by Acoustic Emission Method
}

\author{
T. Boczar*, P. Witkowski, S. Borucki and A. Cichoń \\ Faculty of Electrical Engineering, Automatic Control and Computer Science, Opole University of Technology, \\ Prószkowska 76, 45-758 Opole, Poland
}

(Received July 1, 2015)

\begin{abstract}
This article deals with the subject matter of improvement of the acoustic emission methods used for location of partial discharges, which may occur inside power transformer insulation systems. Analytical solutions of spherical equations for location of partial discharge generation using the acoustic method were shown in detail. Presented in the article method of solving the assumed equations is based on the analytical method and matrix notation. Theoretical considerations and later the measurement-based verification refer to the use of the triangulation method for location of the occurrence of partial discharges. The results of the scientific and research works that have been presented in this article are the next stage of research aimed at development of on-line diagnosis system for insulation systems of electrical equipment, allowing for detection, measurement and identification of forms and locations of partial discharges using the acoustic emission method.
\end{abstract}

DOI: $10.12693 /$ APhysPolA.128.299

PACS: 43.40.-r, 43.40.Vn, 43.58.Wc

\section{Introduction}

Introducing the science-research and then implementation works on the acoustic emission (AE) method generated by partial discharges (PDs) to the assessment of insulation state of electrical power devices was directly influenced by metrological challenges that occur during diagnostic measurements performed under industrial conditions when electric methods are used. Under normal operating conditions of high power transformers, measuring PDs using electric methods is not possible due to high level of electromagnetic interferences. However, a serious problem in the gas chromatography method is its relatively high sensitivity on collection, storage and transport to the laboratory of the insulating oil samples for analysis purposes. However, information on the occurrence, intensity and location of PDs in insulating systems is essential for the tested insulation condition assessment, and thus for proper forecasting of further faultless operation of the diagnosed device. To determine the duration of faultless operation of the tested devices is closely related not only with the scientific and cognitive aspect, but above all, in the competitive electricity market, has a significant and measurable financial impact [1-5].

It should be emphasized that despite the conducted, since the late 70's of the last century, intensive and multidirectional scientific and research works aimed at improvement of the AE method for assessment of PDs, this method does not replace the currently used ones but only, by giving new indicator characterizing insulation, it may constitute their important complement. Thereby, the AE method fills the gap that existed in the metrology of PDs

*corresponding author; e-mail: t.boczar@po.opole.pl generated in insulating systems of high voltage devices. In addition, it should be noted that the range of the $\mathrm{AE}$ method applications may be limited, among others, by the following factors: high level of acoustic interferences, complex geometry of the measured objects that prevents attachment to the surface of measurement sensors and application of dielectric or insulation systems with low elasticity and complex geometric structure [6-14].

Currently, the AE method allows for detection that is, determining the occurrence of PDs directly in insulation of the electric power device that is in use. However, a significant challenge is to measure the intensity and volumes of partial discharges measured by the $\mathrm{AE}$ method. It is caused by occurrence of the AE signals as propagation generated by PDs of multi-layer insulation. This problem is also important when determining location of PDs in insulating systems based on the obtained results from measurements of AE signals [6-15].

Acoustic wave produced by PD generation being dispersed inside the transformer is subject to physical phenomena, which include: refraction, absorption, deflection, dispersion and attenuation. Parameters of the propagation path of AE signals affect the results of the analysis in time, frequency and time-frequency $[5,10,11,16]$. Therefore, an important problem is to determine the length and value parameters of prolongation path of the acoustic wave generated by PDs. It should be stressed that for high power transformer units, the distance between the measurement sensor recording $\mathrm{AE}$ signals and the source of PDs can be even several meters. In addition, their insulation systems have complex composition and construction, which significantly affects the difficulty of determining parameters of propagation path of the emitted $\mathrm{AE}$ waves.

Most of the ongoing works related to improvement of diagnostics of transformers using the EA method refers 
to the detection problem of basic forms of PDs associated with a specific defect of the tested insulation [1722 . However, the subject of this article is the location of PD generation using the triangulation method, modified by the authors, with application of the Rogowski coil. As a result of proper location of PDs and linking those with a particular part of the insulation system will allow assessing the hazard level for the tested insulation, and thus it can reduce the need for the entire system modernization. Depending on the location of PDs, the owner of the transformer being diagnosed can undertake certain actions to eliminate their causes.

In the measuring praxis two primary PD localization methods are applied based on whose numerous modifications and improvements came into existence. First of them is the highest loudness method which is based on discovering the highest amplitude values of the AE signal in the area of a transformer tank. The second one, called triangular method, is based on measurement of delay times with which the AE signals generated by $\mathrm{PD}$ arrive at measuring transducer mounted at different places on the investigated transformer tank surface (Fig. 1). Works aimed at improvement of the method based on estimation of the AE signal arrival direction recorded by using sensor matrix are also performed [15].

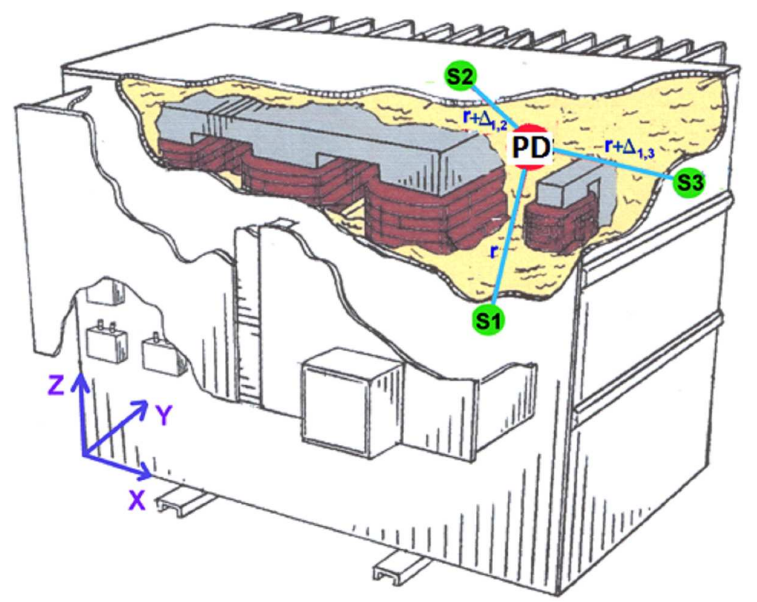

Fig. 1. Pictoral view of the triangular method for PD measurement in a transformer model, where: PD generation position of a partial discharge; s1, s2, s3 mounting location of measuring transducers; $r, r+\Delta 1,2$, $\mathrm{r}+\Delta 1,3$ - acoustic emission propagation path from the PD source to the transducer.

Presented in the further part of the paper theoretical considerations and measurements results regard improvement of the estimation apparatus which is applied for localization of PD generation positions by use of the triangular method.

In the case when a small number of transducers are applied for delay time measurement there exists a problem with estimation of the time that elapsed from PD appearance to this event registered by the first measuring transducer. The other AE signal delay times are read out from the time runs as the difference between successive times registered. For solution of this problem electric signals which occur by PD and are measured by the Rogowski coil have been applied. Detailed explanation of this problem is presented in [1-3]. In this paper we concentrate just on solution and presentation of the spherical equations.

\section{Method of solving equations}

It was assumed that inside the transformer tank a PD appears in a point $P$ with coordinates: $x, y, z$. On the tank outer surface three measuring transducers, labeled as: $S 1, S 2, S 3$, are mounted at positions with following coordinates respectively: $x S 1, y S 1, z S 1 ; x S 2, y S 2, z S 2$, and $x S 3, y S 3, z S 3$ (Fig. 2).

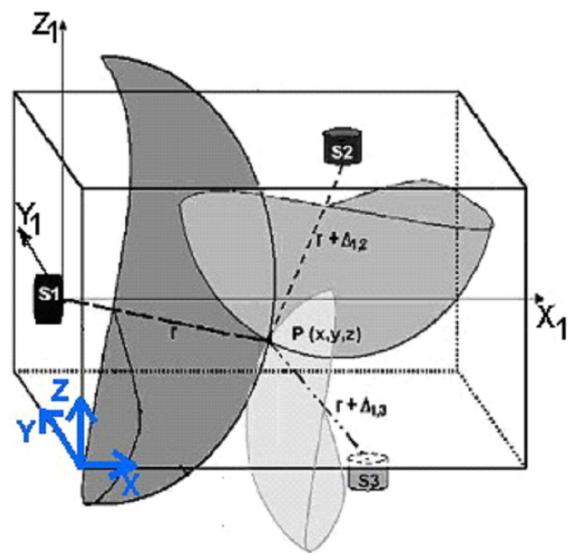

Fig. 2. Graphical interpretation of intersecting areas applied for PD localization [4].

In the mathematical equations describing the triangular method it can be assumed that transducers location points are to be found in the center of the particular areas and its radii $\left(r, r+\Delta_{12}, r+\Delta_{13}\right)$ are products of the acoustic wave propagation velocity $\left(V_{p}\right)$ and the time needed for the route from PD source to the transducer. The dependencies (1)-(3) which describe the areas formatted reflect the fact that to the particular transducers $S 1, S 2, S 3$ the AE signals arrive with delay $\tau$. Solution of the equation set consisting of (1)-(3) is the intersection position of determined areas and the PD source location [1-3, 5].

$$
\begin{aligned}
& \left(x-x_{S 1}\right)^{2}+\left(y-y_{S 1}\right)^{2}+\left(z-z_{S 1}\right)^{2}=\left(V_{p} * T\right)^{2}, \\
& \left(x-x_{S 2}\right)^{2}+\left(y-y_{S 2}\right)^{2}+\left(z-z_{S 2}\right)^{2}= \\
& {\left[V_{p} *\left(\tau_{2}+T\right)\right]^{2}} \\
& \left(x-x_{S 3}\right)^{2}+\left(y-y_{S 3}\right)^{2}+\left(z-z_{S 3}\right)^{2}= \\
& {\left[V_{p} *\left(\tau_{3}+T\right)\right]^{2}}
\end{aligned}
$$

where $x, y, z-$ PD source coordinates; $\left(x_{S 1}, y_{S 1}, z_{S 1}\right),\left(x_{S 2}, y_{S 2}, z_{S 2}\right),\left(x_{S 3}, y_{S 3}, z_{S 3}\right) \quad$ - location of the measuring transducers $S 1, S 2, S 3 ; V_{p}$ velocity of the acoustic wave propagation in a given 
medium; $\tau_{2}, \tau_{3}$ - delay time of the signal arrival to the transducers $S 2, S 3 ; T$ - time which elapsed from the PD appearance to its registration by the first transducer $S 1$.

In Eqs. (1)-(3) the variables: $T, \tau_{2}, \tau_{3}, V_{p}, x_{S 1}, y_{S 1}$, $z_{S 1}, x_{S 2}, y_{S 2}, z_{S 2}, x_{S 3}, y_{S 3}, z_{S 3}$ are known. The first three are read out from the time runs (Fig. 3), $V_{p}$ is a table value, the others are known coordinates of the measuring transducers. The unknown parameters are coordinates of the point $P(x, y, z)$, whose values are to be estimated. For this purpose an analytical equation set solution method has been applied. In order to reduce mathematical description the following variables have been assumed:

$$
\begin{aligned}
& \left(V_{p} T\right)^{2}=a, x_{S 1}=x_{1}, y_{S 1}=y_{1}, z_{S 1}=z_{1}, \\
& {\left[V_{p}\left(\tau_{2}+T\right)\right]^{2}=b, x_{S 2}=x_{2}, y_{S 2}=y_{2}, z_{S 2}=z_{2},} \\
& {\left[V_{p}\left(\tau_{3}+T\right)\right]^{2}=c, x_{S 3}=x_{3}, y_{S 3}=y_{3}, z_{S 3}=z_{3} .}
\end{aligned}
$$

From this Eqs. (4)-(6) arise

$$
\begin{aligned}
& \left(x-x_{1}\right)^{2}+\left(y-y_{1}\right)^{2}+\left(z-z_{1}\right)^{2}=a, \\
& \left(x-x_{2}\right)^{2}+\left(y-y_{2}\right)^{2}+\left(z-z_{2}\right)^{2}=b, \\
& \left(x-x_{3}\right)^{2}+\left(y-y_{3}\right)^{2}+\left(z-z_{3}\right)^{2}=c .
\end{aligned}
$$

Subtracting by sides from Eq. (5) Eq. (4) and from (6) Eq. (4), dependences (7) and (8) have been determined

$$
\begin{aligned}
& \left(x-x_{2}\right)^{2}-\left(x-x_{1}\right)^{2}+\left(y-y_{2}\right)^{2}-\left(y-y_{1}\right)^{2} \\
& \quad+\left(z-z_{2}\right)^{2}-\left(z-z_{1}\right)^{2}=b-a, \\
& \left(x-x_{3}\right)^{2}-\left(x-x_{1}\right)^{2}+\left(y-y_{3}\right)^{2}-\left(y-y_{1}\right)^{2} \\
& \quad+\left(z-z_{3}\right)^{2}-\left(z-z_{1}\right)^{2}=c-a .
\end{aligned}
$$

Using short multiplication formula $\left\{(a+b)(a-b)=a^{2}-b^{2}\right\} \quad$ Eq. (7) becomes to dependence (9), and after simplification to (10):

$$
\begin{aligned}
& \left(x-x_{2}+x-x_{1}\right)\left(x-x_{2}-x+x_{1}\right) \\
& \quad+\left(y-y_{2}+y-y_{1}\right)\left(y-y_{2}-y+y_{1}\right) \\
& \quad+\left(z-z_{2}+z-z_{1}\right)\left(z-z_{2}-z+z_{1}\right)=b-a, \\
& \left(2 x-x_{1}-x_{2}\right)\left(x_{1}-x_{2}\right)+\left(2 y-y_{1}-y_{2}\right)\left(y_{1}-y_{2}\right) \\
& \quad+\left(2 z-z_{1}-z_{2}\right)\left(z_{1}-z_{2}\right)=b-a .
\end{aligned}
$$

Using simple mathematical transformations (11)-(13) Eq. (10) was transformed to a linear equation of the form $A x+B y=C$ :

$$
\begin{aligned}
& 2 x\left(x_{1}-x_{2}\right)-\left(x_{1}+x_{2}\right)\left(x_{1}-x_{2}\right)+2 y\left(y_{1}-y_{2}\right) \\
& \quad-\left(y_{1}+y_{2}\right)\left(y_{1}-y_{2}\right)+2 z\left(z_{1}-z_{2}\right) \\
& \quad-\left(z_{1}+z_{2}\right)\left(z_{1}-z_{2}\right)=b-a, \\
& 2 x\left(x_{1}-x_{2}\right)+2 y\left(y_{1}-y_{2}\right)=\left(x_{1}+x_{2}\right)\left(x_{1}-x_{2}\right) \\
& \quad+\left(y_{1}+y_{2}\right)\left(y_{1}-y_{2}\right)+\left(z_{1}+z_{2}\right)\left(z_{1}-z_{2}\right) \\
& \quad-2 z\left(z_{1}-z_{2}\right)+b-a, \\
& 2 x\left(x_{1}-x_{2}\right)+2 y\left(y_{1}-y_{2}\right)=x_{1}^{2}-x_{2}^{2}+y_{1}^{2}-y_{2}^{2} \\
& \quad+z_{1}^{2}-z_{2}^{2}-2 z\left(z_{1}-z_{2}\right)+b-a .
\end{aligned}
$$

Equation (13) was multiplied bilaterally by (-1) and transformed to dependence (14):

$$
\begin{gathered}
2 x\left(x_{2}-x_{1}\right)+2 y\left(y_{2}-y_{1}\right)=x_{2}^{2}-x_{1}^{2}+y_{2}^{2} \\
-y_{1}^{2}+z_{2}^{2}-z_{1}^{2}-2 z\left(z_{2}-z_{1}\right)-b+a .
\end{gathered}
$$

Analogically the dependence (8) was transformed to dependence (15):

$$
\begin{gathered}
2 x\left(x_{3}-x_{1}\right)+2 y\left(y_{3}-y_{1}\right)=x_{3}^{2}-x_{1}^{2}+y_{3}^{2} \\
-y_{1}^{2}+z_{3}^{2}-z_{1}^{2}-2 z\left(z_{3}-z_{1}\right)-b+a .
\end{gathered}
$$

On the basis of unknowns from (14), (15) the matrix (16) was written and its determinant (17) and matrix (18) are determined from Eqs. (14) and (15):

$$
\begin{aligned}
& A=\left|\begin{array}{ll}
2\left(x_{2}-x_{1}\right) & 2\left(y_{2}-y_{1}\right) \\
2\left(x_{3}-x_{1}\right) & 2\left(y_{3}-y_{1}\right)
\end{array}\right|, \\
& \operatorname{det} A=2\left(x_{2}-x_{1}\right) 2\left(y_{3}-y_{1}\right)-2\left(y_{2}-y_{1}\right) 2\left(x_{3}-x_{1}\right) \text {, } \\
& A_{1}= \\
& x_{2}^{2}-x_{1}^{2}+y_{2}^{2}-y_{1}^{2}+z_{2}^{2}-z_{1}^{2}-2 z\left(z_{2}-z_{1}\right)-b+a \quad 2\left(y_{2}-y_{1}\right) \\
& x_{3}^{2}-x_{1}^{2}+y_{3}^{2}-y_{1}^{2}+z_{3}^{2}-z_{1}^{2}-2 z\left(z_{3}-z_{1}\right)-b+a \quad 2\left(y_{3}-y_{1}\right)
\end{aligned}
$$

In the successive step using determinants $x=$ $\operatorname{det} A_{1} / \operatorname{det} A$ and ordering elements in terms of unknowns $x, y, z$, Eq. (19) was determined

$$
\begin{aligned}
x & =\frac{\left(z_{3}-z_{1}\right)\left(y_{2}-y_{1}\right)-\left(z_{2}-z_{1}\right)\left(y_{3}-y_{1}\right)}{\left(x_{2}-x_{1}\right)\left(y_{3}-y_{1}\right)-\left(y_{2}-y_{1}\left(x_{3}-x_{1}\right)\right.} z \\
& +\frac{\left(y_{3}-y_{1}\right)\left(x_{2}^{2}-x_{1}^{2}+y_{2}^{2}-y_{1}^{2}+z_{2}^{2}-z_{1}^{2}-b+a\right)}{2\left(x_{2}-x_{1}\right)\left(y_{3}-y_{1}\right)-\left(y_{2}-y_{1}\left(x_{3}-x_{1}\right)\right.} \\
& -\frac{\left(y_{2}-y_{1}\right)\left(x_{3}^{2}-x_{1}^{2}+y_{3}^{2}-y_{1}^{2}+z_{3}^{2}-z_{1}^{2}-b+a\right)}{2\left(x_{2}-x_{1}\right)\left(y_{3}-y_{1}\right)-\left(y_{2}-y_{1}\left(x_{3}-x_{1}\right)\right.} .
\end{aligned}
$$

In order to simplify Eq. (19) the following designations were introduced: $\alpha, \beta-(20)$ and (21). Further, according to them equation (22) was written

$$
\begin{gathered}
\alpha=\frac{\left(z_{3}-z_{1}\right)\left(y_{2}-y_{1}\right)-\left(z_{2}-z_{1}\right)\left(y_{3}-y_{1}\right)}{\left(x_{2}-x_{1}\right)\left(y_{3}-y_{1}\right)-\left(y_{2}-y_{1}\left(x_{3}-x_{1}\right)\right.} \\
\beta=\frac{\left(y_{3}-y_{1}\right)\left(x_{2}^{2}-x_{1}^{2}+y_{2}^{2}-y_{1}^{2}+z_{2}^{2}-z_{1}^{2}-b+a\right)}{2\left(x_{2}-x_{1}\right)\left(y_{3}-y_{1}\right)-\left(y_{2}-y_{1}\left(x_{3}-x_{1}\right)\right.} \\
-\frac{\left(y_{2}-y_{1}\right)\left(x_{3}^{2}-x_{1}^{2}+y_{3}^{2}-y_{1}^{2}+z_{3}^{2}-z_{1}^{2}-b+a\right)}{2\left(x_{2}-x_{1}\right)\left(y_{3}-y_{1}\right)-\left(y_{2}-y_{1}\left(x_{3}-x_{1}\right)\right.} \\
x=\alpha z+\beta .
\end{gathered}
$$

Analogically using determinants $y=\operatorname{det} A_{2} / \operatorname{det} A$ was estimated and after variables ordering Eq. (23) was written.

$$
\begin{aligned}
y & =\frac{\left(z_{2}-z_{1}\right)\left(x_{3}-x_{1}\right)-\left(z_{3}-z_{1}\right)\left(x_{2}-x_{1}\right)}{\left(x_{2}-x_{1}\right)\left(y_{3}-y_{1}\right)-\left(y_{2}-y_{1}\left(x_{3}-x_{1}\right)\right.} z \\
& +\frac{\left(x_{2}-x_{1}\right)\left(x_{3}^{2}-x_{1}^{2}+y_{3}^{2}-y_{1}^{2}+z_{3}^{2}-z_{1}^{2}-b+a\right)}{2\left(x_{2}-x_{1}\right)\left(y_{3}-y_{1}\right)-\left(y_{2}-y_{1}\left(x_{3}-x_{1}\right)\right.} \\
& -\frac{\left(x_{3}-x_{1}\right)\left(x_{2}^{2}-x_{1}^{2}+y_{2}^{2}-y_{1}^{2}+z_{2}^{2}-z_{1}^{2}-b+a\right)}{2\left(x_{2}-x_{1}\right)\left(y_{3}-y_{1}\right)-\left(y_{2}-y_{1}\left(x_{3}-x_{1}\right)\right.} .
\end{aligned}
$$


In order to simplify further formulae and their interpretation Eq. (23) was written as (26) by use of dependences (24) and (25):

$$
\begin{gathered}
\alpha^{\prime}=\frac{\left(z_{2}-z_{1}\right)\left(x_{3}-x_{1}\right)-\left(z_{3}-z_{1}\right)\left(x_{2}-x_{1}\right)}{\left(x_{2}-x_{1}\right)\left(y_{3}-y_{1}\right)-\left(y_{2}-y_{1}\left(x_{3}-x_{1}\right)\right.}, \\
\beta^{\prime}=\frac{\left(x_{2}-x_{1}\right)\left(x_{3}^{2}-x_{1}^{2}+y_{3}^{2}-y_{1}^{2}+z_{3}^{2}-z_{1}^{2}-b+a\right)}{2\left(x_{2}-x_{1}\right)\left(y_{3}-y_{1}\right)-\left(y_{2}-y_{1}\left(x_{3}-x_{1}\right)\right.} \\
-\frac{\left(x_{3}-x_{1}\right)\left(x_{2}^{2}-x_{1}^{2}+y_{2}^{2}-y_{1}^{2}+z_{2}^{2}-z_{1}^{2}-b+a\right)}{2\left(x_{2}-x_{1}\right)\left(y_{3}-y_{1}\right)-\left(y_{2}-y_{1}\left(x_{3}-x_{1}\right)\right.}, \\
y=\alpha^{\prime} z+\beta^{\prime}, \\
\left(\alpha z+\beta-x_{1}\right)^{2}+\left(\alpha^{\prime} z+\beta^{\prime}-y_{1}\right)^{2}+\left(z-z_{1}\right)^{2}=a .
\end{gathered}
$$

Using short multiplication formulae in (27) Eq. (28) was written

$$
\begin{gathered}
z^{2}\left(\alpha^{2}+\alpha^{\prime 2}+1\right)+z\left(2 \alpha \beta+2 \alpha^{\prime} \beta^{\prime}-2 \alpha x_{1}-2 \alpha^{\prime} y_{1}-2 z_{1}\right) \\
\quad+x_{1}^{2}+y_{1}^{2}+z_{1}^{2}+\beta^{2}+\beta^{\prime 2}-2 \beta x_{1}-2 \beta^{\prime} y_{1}-a=0 . \quad(28)
\end{gathered}
$$

For the quadratic Eq. (28) the $\Delta(29)$ was determined and its solutions were calculated: $z^{(1)}$ and $z^{(2)}(30)$ :

$$
\begin{aligned}
\Delta & =\left(2 \alpha \beta+2 \alpha^{\prime} \beta^{\prime}-2 \alpha x_{1}-2 \alpha^{\prime} y_{1}-2 z_{1}\right)^{2} \\
& -4\left(\alpha^{2}+\alpha^{2}+1\right)\left(x_{1}^{2}+y_{1}^{2}+z_{1}^{2}+\beta^{2}\right. \\
& \left.+\beta^{\prime 2}-2 \beta x_{1}-2 \beta^{\prime} y_{1}-a\right), \\
z^{(1,2)} & =\frac{-\left(2 \alpha \beta+2 \alpha^{\prime} \beta^{\prime}-2 \alpha x_{1}-2 \alpha^{\prime} y_{1}-2 z_{1}\right) \pm \sqrt{\Delta}}{2\left(\alpha^{2}+\alpha^{\prime 2}+1\right)} .
\end{aligned}
$$

According to (30) the other unknowns, $x$ and $y$, were determined by use of Eqs. (31) and (32):

$$
\begin{aligned}
& x^{(1,2)}=\alpha z^{(1,2)}+\beta, \\
& y^{(1,2)}=\alpha^{\prime} z^{(1,2)}+\beta^{\prime} .
\end{aligned}
$$

The equation set (4)-(6) solution presented can be implemented with arbitrary computer software that enables for perform mathematical calculations (e.g. Mathematica, Mathad) or in a spreadsheet program. The disadvantage of this solution is the fact that achieved results are considerably matter dependent on the accuracy of parameters introduced. Therefore, in many cases which reflect real measuring conditions the achieved solutions indicate little precision and are often even incorrect.

Because Eqs. (20), (21), (24), (25), (29), (30) have comparatively complicated structure in the scope of considerations performed, results of which are presented in the paper, other solution way was presented. For this purpose the matrix description was applied.

Variables $x, y, z$ are designed as $x^{(1)}, x^{(2)}, x^{(3)}$, which has enabled for description of variables in form of a vector in $\mathbf{R}^{3}$ space. Analogically coordinate vectors of the measuring transducers, mounted in the midpoints of areas with radii $r_{1}, r_{2}, r_{3}$ were written. Designations introduced are described by formulae (33) and (34):

$$
\bar{X}=\left|\begin{array}{l}
x^{(1)} \\
x^{(2)} \\
x^{(3)}
\end{array}\right|
$$

$$
\bar{S}_{1}=\left|\begin{array}{c}
s_{1}^{(1)} \\
s_{1}^{(2)} \\
s_{1}^{(3)}
\end{array}\right|, \quad \bar{S}_{2}=\left|\begin{array}{c}
s_{2}^{(1)} \\
s_{2}^{(2)} \\
s_{2}^{(3)}
\end{array}\right|, \quad \bar{S}_{3}=\left|\begin{array}{c}
s_{3}^{(1)} \\
s_{3}^{(2)} \\
s_{3}^{(3)}
\end{array}\right| .
$$

On the basis of Eqs. (4), (33) and (34) dependence (35) was written in canonical form for the first area. Further, using short multiplication formulae it was expanded to (36) and in consequence transformed into matrix form described by formulae (37) and (38):

$$
\begin{gathered}
\left(x^{(1)}-s_{1}^{(1)}\right)^{2}+\left(x^{(2)}-s_{1}^{(2)}\right)^{2}+\left(x^{(3)}-s_{1}^{(3)}\right)^{2}=r_{1}^{2}, \\
\left(x^{(1)}\right)^{2}+\left(x^{(2)}\right)^{2}+\left(x^{(3)}\right)^{2}-2\left[\begin{array}{ll}
x^{(1)} s_{1}^{(1)}+x^{(2)} s_{1}^{(2)}+x^{(3)} s_{1}^{(3)}
\end{array}\right] \\
+\left(s_{1}^{(1)}\right)^{2}+\left(s_{1}^{(2)}\right)^{2}+\left(s_{1}^{(3)}\right)^{2}=r_{1}^{2}, \\
{\left[\begin{array}{lll}
x^{(1)} & x^{(2)} & x^{(3)}
\end{array}\right]\left|\begin{array}{l}
x^{(1)} \\
x^{(2)} \\
x^{(3)}
\end{array}\right|-2\left[\begin{array}{lll}
x^{(1)} & x^{(2)} & x^{(3)}
\end{array}\right]\left|\begin{array}{c}
s_{1}^{(1)} \\
s_{1}^{(2)} \\
s_{1}^{(3)}
\end{array}\right|} \\
+\left[\begin{array}{lll}
s_{1}^{(1)} & s_{1}^{(2)} & s_{1}^{(3)}
\end{array}\right]\left|\begin{array}{l}
s_{1}^{(1)} \\
s_{1}^{(2)} \\
s_{1}^{(3)}
\end{array}\right|=r_{1}^{2}, \\
\bar{X}^{\mathrm{T}} \bar{X}-2 \bar{X}^{\mathrm{T}} \bar{S}_{1}+\bar{S}_{1}^{\mathrm{T}} \bar{S}_{1}=r_{1}^{2} .
\end{gathered}
$$

Analogically transformations of Eqs. (5) and (6) were performed, respectively, for the measuring transducers 2 and 3. Equations written in matrix form (39) and (40) have been estimated

$$
\begin{aligned}
& \bar{X}^{\mathrm{T}} \bar{X}-2 \bar{X}^{\mathrm{T}} \bar{S}_{2}+\bar{S}_{2}^{\mathrm{T}} \bar{S}_{2}=r_{2}^{2}, \\
& \bar{X}^{\mathrm{T}} \bar{X}-2 \bar{X}^{\mathrm{T}} \bar{S}_{3}+\bar{S}_{3}^{\mathrm{T}} \bar{S}_{3}=r_{3}^{2} .
\end{aligned}
$$

The position of $\mathrm{PD}$ occurrence has its coordinates in the intersection point of the particular areas, thus it is the solution of equations set (41):

$$
\left\{\begin{array}{c}
\bar{X}^{\mathrm{T}} \bar{X}-2 \bar{X}^{\mathrm{T}} \bar{S}_{1}+\bar{S}_{1}^{\mathrm{T}} \bar{S}_{1}=r_{1}^{2}, \\
\bar{X}^{\mathrm{T}} \bar{X}-2 \bar{X}^{\mathrm{T}} \bar{S}_{2}+\bar{S}_{2}^{\mathrm{T}} \bar{S}_{2}=r_{2}^{2}, \\
\bar{X}^{\mathrm{T}} \bar{X}-2 \bar{X}^{\mathrm{T}} \bar{S}_{3}+\bar{S}_{3}^{\mathrm{T}} \bar{S}_{3}=r_{3}^{2} .
\end{array}\right.
$$

Based on the Gauss elimination method an algorithm was implemented and the equation set (41) was solved [1-3].

\section{Verification of the achieved results by measurements}

In order to verify results achieved by use of the presented above set of Eqs. (41) with real data a PD modeling spark gap (PDs in the point-point system in oil, which can be related to PDs generated by insulation damage of two neighboring turns of winding of a transformer) mounted in a transformed tank filled with insulation oil was applied. On a bushing isolator that supplies the investigated modeling system, a Rogowski coil was mounted. During PD appearance the coil generates signals which are then transferred to an integrating-filtering circuit for triggering of the measuring system. On the opposite sides of the tank three piezoelectric transducers were mounted. The AE signal measured was transferred through filters and amplifiers circuit and was registered 
by a measuring card to which also the signal from the Rogowski coil was attached for triggering [1-3].

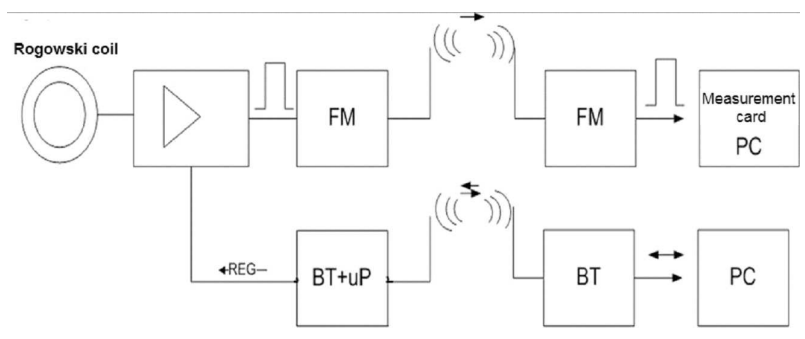

Fig. 3. The block diagram of wireless track of transmission signal beginning of measurements: FM - the transmitter/the radioreceiver of modulation FM, BT the module of transmission bluetooth, PC - the measuring computer with master software.

During tests, the Rogowski coil will serve as a measurement card trigger, when installed directly on the supply lines or bushings of electric power transformers that in normal operation are at high potential, which in adverse conditions can cause damage to the measurement path. Therefore, authors of this article suggested an alternative method for electrical signal transmission caused by coil response to the trigger of the card using radio transmission. The constructed wireless transmission system consists of two transmission bands. First of which is one-way FM transmitter and receiver used for signal transmission registered by the coil. However, the second band consists of bluetooth bi-directional transmitter and receiver, which is used to control the level of signal, which is detected by the Rogowski coil. The signal is then transmitted with FM band. In order to reduce time delays of the emitted signals, the transmitter was constructed in analogue technique based on circuit of two transistors and several RLC elements. Transmitter allows for smooth adjustment of FM frequencies range between $88 \mathrm{MHz}$ and $108 \mathrm{MHz}$. The receiver, which is also built with analogue components, allows receiving signals in the full bandwidth range from $88 \mathrm{MHz}$ to $108 \mathrm{MHz}$. The proposed wireless triggering measurement card enabled galvanic separation of the high voltage source from elements of the measurement path. Block diagram of the proposed transmission system is shown in Fig. 3. Figures 4 and 5 illustrate a scheme of the constructed wireless transmission path.

During each measurement four data sets were gathered. These were time runs of the $\mathrm{AE}$ signals registered by the three transducers respectively: channel 1 , channel 2 , and channel 3 (Fig. $6 \mathrm{a}-\mathrm{c}$ ) and the time run of the electric signal generated by the Rogowski coil which is presented in Fig. 6d. These signals were used for the analysis performed in the time domain. In order to read precisely the achieved dependences gathered curves were over scaled; the results are presented in Fig. 6e-h.

Detailed description of the measuring system applied, high voltage spark gap for modeling of PD, the

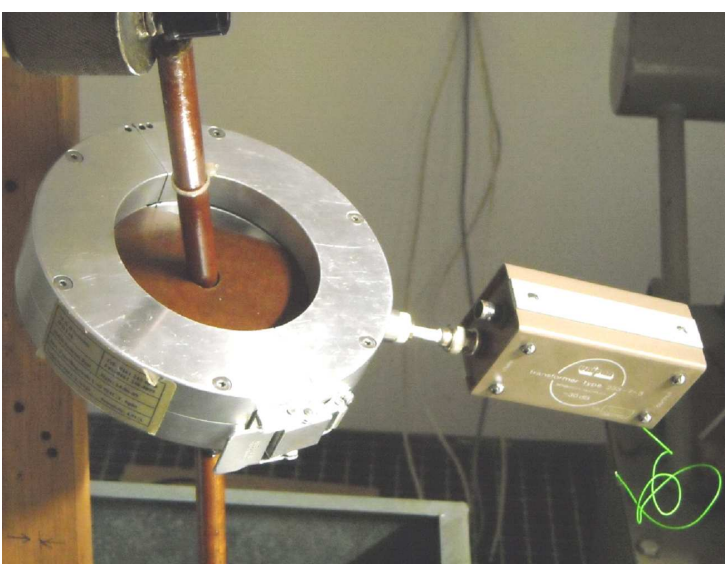

Fig. 4. Photo of the transmitter of wireless transmission of signals from Rogowski coil.

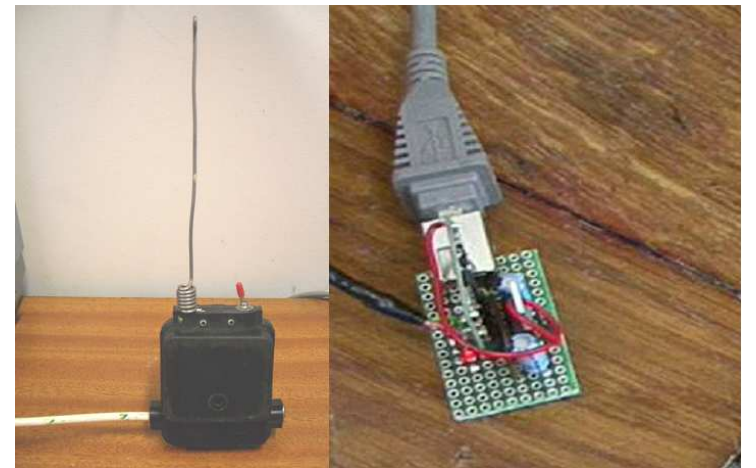

Fig. 5. Photos of the receiver set of wireless transmission of signals from Rogowski coil. a)

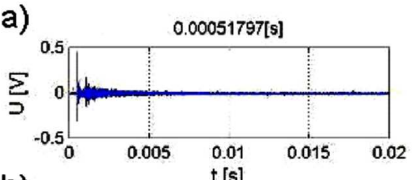

b)
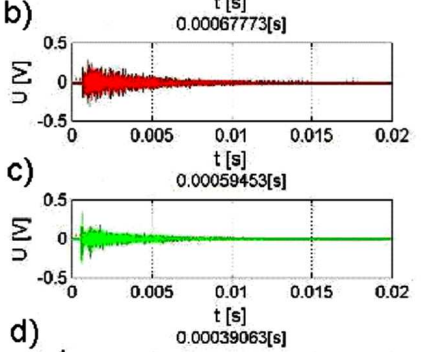

d)

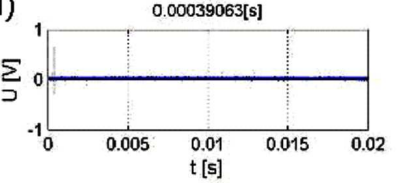

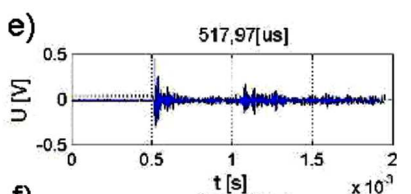
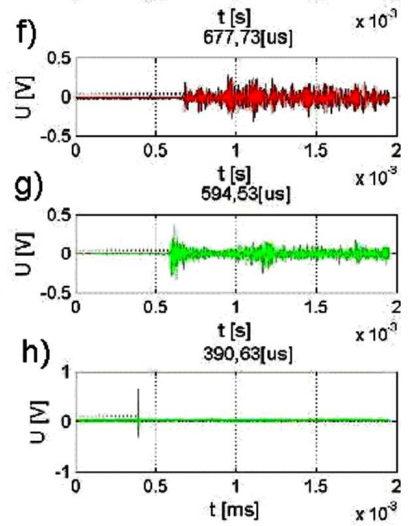

Fig. 6. Time runs of AE signals generated by a spark gap used for $\mathrm{PD}$ modeling for a source occurring in a point with coordinates: $x=41 \mathrm{~cm}, y=28.5 \mathrm{~cm}$, $z=17 \mathrm{~cm}$ mounted in insulation oil. Signals a), b), c) and $\mathrm{e}), \mathrm{f}), \mathrm{g}$ ) were registered with the three transducers, signals $d$ ) and $h$ ) are measured by the Rogowski coil [3]. 
transformer tank and also the metrological conditions and numerical procedures are presented in papers [1-3].

Using data estimated from Fig. 6 and the calculation algorithm, which implements the Gauss elimination method, the set of Eqs. (41) was solved [5, 6]. In this way the following coordinates were estimated $x=39.4 \mathrm{~cm}$, $y=28.8 \mathrm{~cm}, z=18.0 \mathrm{~cm}$ which determine the position of PD appearance (Table I). Actually the source of PD generation was mounted in a point with following coordinates: $x=41.0 \mathrm{~cm}, y=28.5 \mathrm{~cm}, z=17.0 \mathrm{~cm}$. The difference between the real value and the value determined in analytical way equals $1.9 \mathrm{~cm}$ and the standard deviation equals $3.7 \%$.

\section{TABLE I}

Coordinates of the PD source position calculated in analytical way by use of data from Fig. 3. $A$ - actual PD source coordinates, $E$ - estimated PD source coordinates.

\begin{tabular}{c|c|c}
\hline \hline Parameters & $A$ & $E$ \\
\hline $\begin{array}{c}\text { PD source localization } \\
\text { on the } X \text { axis [m] }\end{array}$ & 0.410 & 0.394 \\
$\begin{array}{c}\text { PD source localization } \\
\text { on the } Y \text { axis [m] } \\
\text { PD source localization } \\
\text { on the } Z \text { axis [m] }\end{array}$ & 0.285 & 0.288 \\
\hline \hline $\begin{array}{c}\text { Distance between } \\
\text { midpoints [cm] }\end{array}$ & 0.170 \\
$\begin{array}{c}\text { Standard deviation [\%] } \\
\text { tanding }\end{array}$ & \multicolumn{2}{|c}{3.9} \\
\hline
\end{tabular}

In order to verify the proposed measurement method, by following the methodology described above, attempts were made to detect $\mathrm{PD}$ source location for additional other seven different configurations of location of spark modeling PDs in the blade-plate set for individual measurement sensors. The analysis was carried out for uniform propagation of $\mathrm{AE}$ wave in transformer oil. Changes applied to the location of $\mathrm{PD}$-generation in relation to individual walls of the tank, location of measurement sensors for the source of PDs. For each combination of changes in location of the source as well as measurement sensors, five series of measurements were carried out. Each measurement series was composed of three AE signals from transmitters and one electrical signal generated by the Rogowski coil.

TABLE II

Coordinates $[\mathrm{m}]$ of the actual PD generation source and measurement sensors for different configurations.

\begin{tabular}{c|c|c|c|c|c|c|c|c|c|c|c|c}
\hline \hline \multirow{2}{*}{ No. } & \multicolumn{3}{|c|}{ S1 sensor } & \multicolumn{3}{c|}{ S2 sensor } & \multicolumn{3}{c|}{ S3 sensor } & \multicolumn{3}{c}{ PD source. } \\
\cline { 2 - 5 } & OX & OY & OZ & OX & OY & OZ & OX & OY & OZ & OX & OY & OZ \\
\hline 1 & 0.45 & 0.00 & 0.29 & 0.00 & 0.25 & 0.22 & 0.50 & 0.37 & 0.00 & 0.45 & 0.28 & 0.16 \\
2 & 0.45 & 0.00 & 0.27 & 0.00 & 0.25 & 0.22 & 0.54 & 0.38 & 0.00 & 0.50 & 0.28 & 0.16 \\
3 & 0.45 & 0.00 & 0.27 & 0.00 & 0.25 & 0.22 & 0.60 & 0.50 & 0.00 & 0.50 & 0.29 & 0.30 \\
4 & 0.45 & 0.00 & 0.27 & 0.00 & 0.42 & 0.32 & 0.50 & 0.50 & 0.00 & 0.55 & 0.29 & 0.30 \\
5 & 0.13 & 0.00 & 0.24 & 0.00 & 0.42 & 0.32 & 0.56 & 0.60 & 0.21 & 0.50 & 0.20 & 0.30 \\
6 & 0.46 & 0.26 & 0.00 & 0.80 & 0.30 & 0.27 & 0.42 & 0.00 & 0.21 & 0.45 & 0.28 & 0.16 \\
7 & 0.46 & 0.26 & 0.00 & 0.80 & 0.30 & 0.27 & 0.42 & 0.00 & 0.21 & 0.50 & 0.28 & 0.16
\end{tabular}

In order to verify the correctness of results obtained using the proposed method, indicators determining accuracy of the PD location were introduced. The first indicator, called location error, is a distance between the actual and designated source and is expressed in centimetres. The second indicator defined as percentage location error determines the difference in distance between the actual and designated source for particular directions of Cartesian coordinate system for geometrical dimensions of the transformer tank model. Wherein, its designation was introduced in the form of: $\Delta x_{\%}, \Delta y_{\%}, \Delta z_{\%}$. The values were calculated based on Eq. (42):

$$
\begin{aligned}
\Delta x_{\%} & =\frac{\left|x_{r}-x_{w}\right|}{x_{k}} 100 \%, \quad \Delta y_{\%}=\frac{\left|y_{r}-y_{w}\right|}{y_{k}} 100 \%, \\
\Delta z_{\%} & =\frac{\left|z_{r}-z_{w}\right|}{z_{k}} 100 \%,
\end{aligned}
$$

where $x_{r}, y_{r}, z_{r}$ - actual coordinates of the source, $x_{w}, y_{w}, z_{w}$ - coordinates designated based on measurements, $x_{k}, y_{k}, z_{k}-$ tank dimensions for particular directions.

Table III shows results of PD location for seven different spark-sensor configurations with the coordinates given in Table II.

TABLE III

Results of PD location for different sourcesensor configurations.

\begin{tabular}{c|c|c|c|c|c|c}
\hline \hline & \multicolumn{3}{|c|}{$\begin{array}{c}\text { Actual PD source } \\
\text { coordinates [m] }\end{array}$} & \multicolumn{3}{|c}{$\begin{array}{c}\text { Estimated PD source } \\
\text { coordinates [m] }\end{array}$} \\
\cline { 2 - 7 } & OX & OY & OZ & OX & OY & OZ \\
\hline 1 & 0.450 & 0.280 & 0.160 & 0.456 & 0.262 & 0.157 \\
2 & 0.500 & 0.280 & 0.160 & 0.513 & 0.279 & 0.150 \\
3 & 0.500 & 0.290 & 0.300 & 0.513 & 0.301 & 0.294 \\
4 & 0.550 & 0.290 & 0.300 & 0.538 & 0.290 & 0.294 \\
5 & 0.500 & 0.200 & 0.300 & 0.521 & 0.207 & 0.314 \\
6 & 0.430 & 0.280 & 0.160 & 0.417 & 0.279 & 0.159 \\
7 & 0.230 & 0.280 & 0.160 & 0.211 & 0.285 & 0.150 \\
\hline & Location & Error in accordance & \\
& error & to the tank [\%] & & \\
\cline { 2 - 5 } & [cm] & $\Delta x \%$ & $\Delta y_{\%}$ & $\Delta z_{\%}$ \\
\hline 1 & 1.921 & 0.75 & 3.00 & 0.60 & \\
2 & 1.643 & 1.62 & 0.17 & 2.00 & \\
3 & 1.806 & 1.62 & 1.83 & 1.20 \\
4 & 1.342 & 1.50 & 0.00 & 1.20 \\
5 & 2.619 & 2.62 & 1.17 & 2.80 \\
6 & 1.308 & 1.62 & 0.17 & 0.20
\end{tabular}

\section{Conclusion}

Based on the performed research studies of which results are presented in this article, following conclusions can be drawn:

- percentage error value of PD source location in the direction of $O X, O Y$ and $O Z$ axis designated for dimensions of the tank does not exceed $3 \%$, which indicated a very high accuracy of the proposed modified triangulation method; 
- received maximum error value under $2.63 \mathrm{~cm}$ is $\mathrm{sim}$ ilar to location error values obtained by authors using other means [22], where they indicate, respectively, $\leq 3.36 \mathrm{~cm}$ and $\leq 3.14 \mathrm{~cm}$ for a measuring tank of similar dimensions.

Based on analysis performed and measurements results achieved by use of the AE method it can be stated that inside a homogeneous propagation medium, which is the electro-insulation oil, there is a possibility to localize areas of PD generation. The main advantage of the triangular method is its application opportunity for PD occurrence area localization in insulation systems of electric power transformers during its normal operation - load running under industry conditions. However, accuracy of results achieved depends in a significant manner on proper introduction of parameters connected to propagation of $\mathrm{AE}$ wave in inhomogeneous media which are insulation systems with complicated geometry. This regards such parameters as AE wave propagation velocity and reflection, refraction and attenuation coefficients which depend on physical phenomena appearing on the propagation path.

The scope of further scientifically research works will consider determination of the dependence of various generated by PD AE signal propagation parameters in diverse facilities with complicated structure on the achieved results of PD localization.

\section{Acknowledgments}

The work was co-financed from funds of the National Science Centre (NCS) as part of the OPUS programme, project no. 2013/09/B/ST8/01736.

\section{References}

[1] P. Kurtasz, T. Boczar, P. Witkowski, Przeglad Elektrotechniczny 86, 125 (2010) (in Polish).

[2] P. Witkowski, T. Boczar, Przeglad Elektrotechniczny 84, 94 (2008) (in Polish).

[3] P. Witkowski, T. Boczar, Przeglad Elektrotechniczny 86, 70 (2010) (in Polish).

[4] S.M. Markalous, Detection and Localization of Partial Discharges in Power Transformers Using Acoustic and Electromagnetic Signals, Sierke Verlag Göttingen, Institut für Energieübertragung und Hochspannungstechnik der Universität Stuttgart, 2006.
[5] S. Borucki, IEEE Trans. Power Deliv. 27, 670 (2012).

[6] T. Boczar, IEEE Trans. Dielectr. Electr. Insul. 8, 598 (2001).

[7] P. Witkowski, T. Boczar, P. Kurtasz, Pomiary Automatyka Robotyka 12, 93 (2010) (in Polish).

[8] T. Boczar, D. Zmarzły, Mater. Evaluat. 62, 935 (2004).

[9] D. Wotzka, T. Boczar, D. Zmarzły, Acta Phys. Pol. A 116, 428 (2009).

[10] D. Wotzka, T. Boczar, P. Frącz, Acta Phys. Pol. A 120, 767 (2011).

[11] A. Cichoń, S. Borucki, D. Wotzka, M. Szmajda, Acta Phys. Pol. A 122, 804 (2012).

[12] S. Borucki, T. Boczar, A. Cichoń, Arch. Acoust. 32, Suppl., 291 (2007).

[13] D. Wotzka, A. Cichoń, T. Boczar, Arch. Acoust. 37, 19 (2012).

[14] P. Frącz, IEEE Trans. DEI 20, 1909 (2013).

[15] D. Aschenbrenner, H.G. Kranz, W.R. Rutgers, P. Van den Aardweg, IEEE Trans. DEI 12, 216 (2005).

[16] M.G. Danikas, IEEE Trans. Electron Dev. 28, 1075 (1993).

[17] A.S. Farag, M.H. Shewhdi, X. Jin, C. Wang, T.C. Cheng, X. Dong, S. Gao, W. Jing, Z. Wang, Electric Power Syst. Res. 50, 47 (1999).

[18] E. Grossmann, K. Feser, IEEE Trans. Power Deliv. 20, 158 (2005).

[19] P.J. Moore, I.E. Portugues, I.A. Glover, IEEE Trans. Power Deliv. 21, 528 (2006).

[20] S.M. Strachan, S. Rudd, S.D.J. McArthur, M.D. Judd, S. Meijer, E. Gulski, IEEE Trans. DEI 15, 259 (2008).

[21] M. Szmechta, T. Boczar, P. Fracz, Acta Phys. Pol. A 120, 744 (2011).

[22] P. Frącz, Acta Phys. Pol. A 120, 604 (2011). 